\title{
A SIMPLE MATHEMATICAL MODEL OF WAVE MOTION ON A RUBBLE MOUND BREAKWATER SLOPE
}

\author{
Anton Brandtzaeg, Dr.techn. \\ Professor of Construction and Harbour Engineering \\ Technical University of Norway \\ Trondhe $1 \mathrm{~m}$, Norway
}

\section{A. INTRODUCTIUN}

In the improvement of design criteria for the layer of cover blocks on rubble mound breakwaters important advance has been made in recent years (1), (2), (3). still, some points seem to require further study, among them the effect o the spesific welghts of block material and fluid on the stabi lity of the cover. In this respect the magnitude of the flui acclerations involved, of which little information is availab may be of some importance. For evaluation of the acceleratio as well as for other purposes, a roughly approximate mathemat description of the motion of the water rushing up and down th breakwater front may be of some use.

This motion certainly is neither steady nor uniform. Visual and photographic observation through the glass panel c a wave channel seems to indicate, however, that unsteadiness the more important characteristic of the motion during the ur and downrush proper. It seems reasonable, therefore, to atte a first approximation to a description of the motion by negle ing, to a certain extent, its non-uniformity. Necessarily, $\varepsilon$ the same time also the requirement of continuity must be pari disregarded.

In the following a mathematical model based on this point of view is presented for consideration. It is believec that by means of this model values of displacements, velocitj and accelerations can be calculated, which may reasonably be considered as useful, although quite rough, approximations tr the actual values. For a few particular cases, experimental evidence is reported.

The model has reference only to the up- and downrush proper, that is, to the motion of the water above some limit level, at or somewhat below the still water Line (referred $t_{1}$ hereafter as the S,VL). The motion below this level, where $t$ l downrush meets the oncoming next wave, could hardly be conce of as being uniform. 


\section{A SIMPLE MATHEMATICAL MODEL OF WAVE MOTION ON A RUBBLE MOUND BREAKWATER SLOPE}

The velocities indicated in Figures 5 and 6 indicate that the limiting level, below which the model is not applicable, may be placed considerably lower than the SWL, perhaps even one wave height lower. In the absence of sufficient data the SWL has for the time being been chosen as the limit.

Because during uprush an unknown but not negligible quantity of water will disappear into the breakwater, and also for other reasons, useful numerical results are obtainable only for the case of downrush. Nevertheless the case of uprush has been briefly included, to show that also for that case does the model give a picture of the motion fully compatible with obser. vation.

While the present study aims only at contributing somewhat towards a description of the fluid motion involved, and not at the development of design formulae, still such a description would be pointless if it did not cover that region of the breakwater slope, which in the cases considered, is the critical one with regard to failure by dislocation of cover blocks. This point, therefore, requires some consideration.

Sigurdsson (4), in a very illuminating treatise, recently found that the maximum normal (lifting) force on the cover blocks mostly occurred at the approximate level of lowes wave retreat. With regard to failure in this region, mainly caused by normal forces, the model will be of scant interest. Probably this type of failure is predominant with most breakwaters whose cover layers consist of blocks of regular shape closely stacked with only narrow slots open between them.

However, with regard to cover layers of natural stones placed pell-meli on the breakwater slope, numerous observation among them the very careful ones made by Hedar (2), indicate $t$ ] region about or even above the SWL as the critical one. **) observations during a great number of tests at the River and Harbour Research Laboratory of the Technical University of Nor (referred to hereafter as the RHRL) fully confirmed this resul It seems, therefore, that our model should not be irrelevant to the study of the conditions of failure of rubble mound breakwaters covered by broken rock, placed pell-mell, by far the most common type in Norwegian and apparently also in U.S.A. practice.

As the model can yield numerical results only in the case of downrush, it can be of use only in the study of cases where failure occurs during downrush. This, according to Heda (2), holds true for slopes steeper than about $1: 2,5$. Only a s1 of $1: 1,5$ has been treated here. It is the slope most common $i$ Norwegian practice, and seems to be fairly commonly used also the U.S.A.

*) Out of records from 29 test runs, only 2 included stones be moved from a level slightly more than one wave height below while all records included stones being moved from levels a considerably above, the SWL. ((2), Table 65.1 and 65.2). 


\section{COASTAL ENGINEERING}

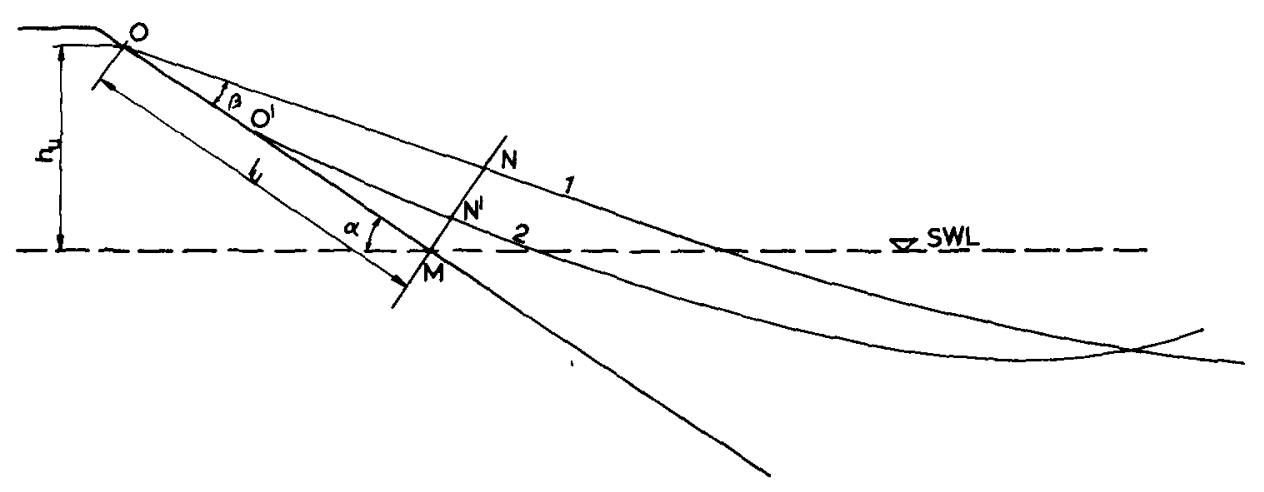

Fig. 1

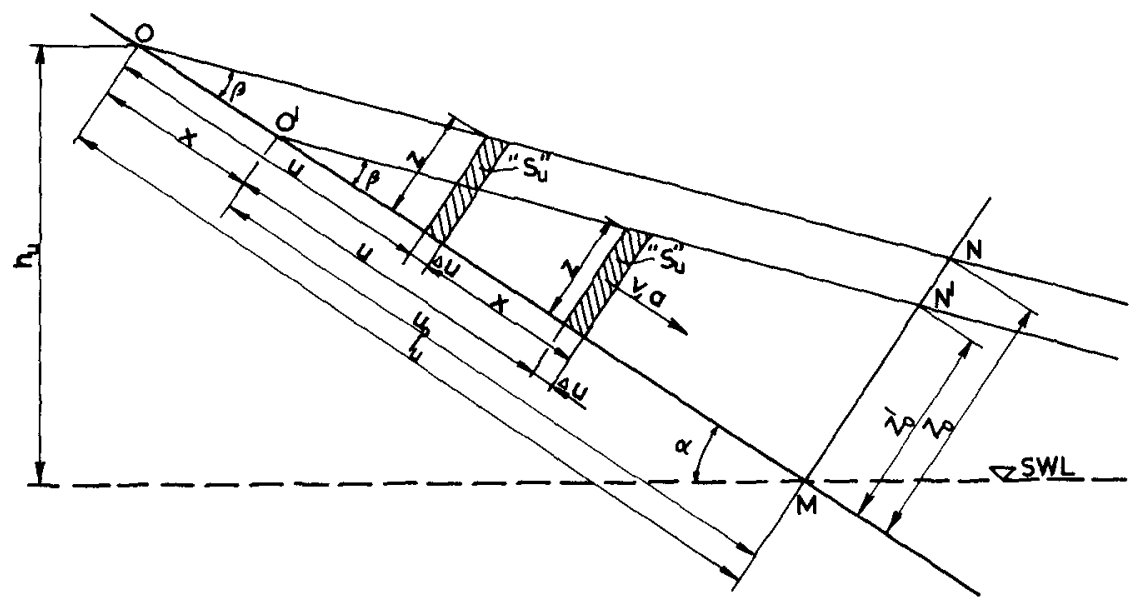

Fig. 2

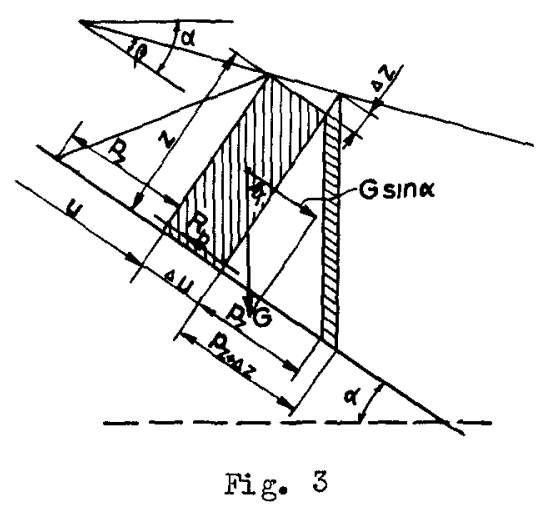

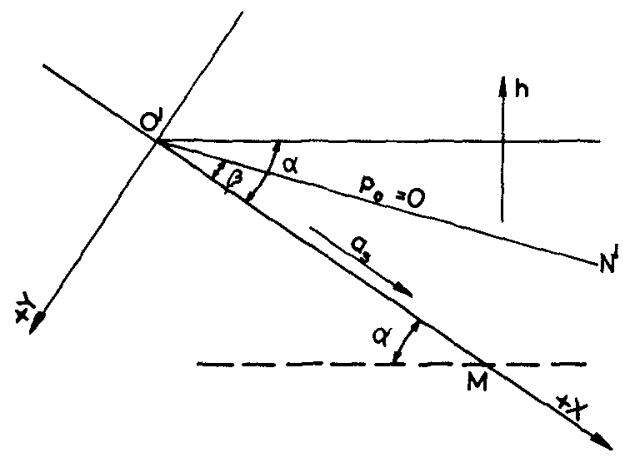

Fig. 4 


\section{A SIMPLE MATHEMATICAL MODEL OF WAVE MOTION \\ ON A RUBBLE MOUND BREAKWATER SLOPE}

\section{B. THE MODEL}

Let thc sketch in Fig. 1 represent the breakwatcr slop and tiro successive profiles of the downrushing wave, profile 1 takcn at the start of downrush and profile 2 at some latcr moment. The hcight of uprush is $h$, corresponding to a distan 1 , along the slope, from the starting point of downrush, 0 , $t$ the Sill. only the body of water above the line MN, will be considered, it being assumed that during downrush the motion above MN will not be significantly influenced by what happens below that line.

The following assumptions wll define the model with regard to downrush (Fig, 2).

1. At the start of downrush, the surface profile, ON, is a straight line, forming the angle, $\beta$, with the breakwater front, OM. Any individual slice, " $S$ ", of the triangular body of water, MON, is defined by its original distance, $u$, from the top of the triangle, 0 , measured along ON. The height of the slice is $z=u \tan \beta$, its width being $\Delta u$.

2. Within each slice the motion of the fluid will be uniform, each slice will move parallel to the slope as a unit, without changc of shape.

3. The several slices will move independently of each other, without regard to continuity of the fluid.

4. The displacement, $x$, of any slice, "S $s_{u}$, from its top position, the velocity of the slice, $v$, and the acceleration, $a$, at the time, $t$, from the start of the motion down the slope can be calculated from the components parallel to the slope of the forces acting on the slicc. These forces arc: the weight of the slice, the pressure dxfference betwecn the two sides of the sluce duc to the difference in slope between the breakwater front and the surface of the fluid, and the forces acting on the slice from the rough cover layer, equal of magn] tude and opposite of direction to the parallel forces acting on the cover blocks from the fluid. It is assumed that the pressure forces will be practically the same as if the fluid werc an ideal one, with no boundary influence, while the force from the cover layer can be approximately calculated independe ly of the other two, and can, without too much error in the $f$ : result, bc considered as acting at the center of gravity of tl slice.

By calculation of the displacement, $x$, of neighbourin slices, the extent of discontinuxty involved in the model may be evaluated. This point will be considered in section F. 


\section{COASTAL ENGINEERING}

\section{FORCES ACTING ON THE SLICE "S $u$ "}

On the assumptions stated in Section $B$, the componer parallel to the slope of the forces acting on any slice, pej unit of depth, normal to the paper, can be calculated as follows, (Fig. 3):

1. The weight of the slice, G. Ignoring the small uppe

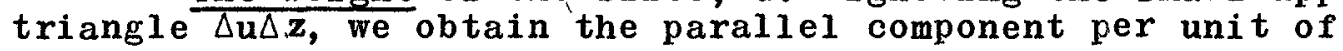
depth:

$$
G \sin \alpha=z \Delta u \gamma_{f} \sin \alpha
$$

2. The pressures on the upper and lower sides of the slice.

Assuming the fluid to be ideal, and taking no accoun of boundary effects, we may derive the pressure distribution in the down-rushing body of fluid from the well known Euler equation, according to which the acceleration in any directi s, is :

$$
a_{s}=-\frac{1}{\rho} \frac{\delta}{\delta_{s}}\left(p+\gamma_{f} h\right)
$$

where $p$ is the pressure at any point and $h$ is the vertical elevation of that point, positive upwards. Using the axes o co-ordinates shorn in Fig. 4, we obtain for the direction no to the slope:

$$
a_{y}=0=-\frac{1}{\rho} \frac{\delta_{p}}{\delta y}+9 \cos \alpha
$$

Taking the pressure at the surface $O^{\prime} N$ ' to be zero, find that under the assumptions stated, the pressure at any $x, y$, in the fluid, will be:

$$
p=\gamma_{f}(x \tan \beta+y) \cos \alpha
$$

The total resultant pressure upwards along the slope per unit of depth of the slice, perpendicular to the paper, will be (Fig. 4):

$$
F_{p}=\gamma_{f} z \cdot \Delta u \tan \beta \cos \alpha
$$

3. The boundary resistance along the breakwater front, I

This resistance obviously is related as well to the velocity as to the acceleration of the fluid. There seems tc a difference of opinion as to whether or not the two effects 


\section{A SIMPLE MATHEMATICAL MODEL OF WAVE MOTION ON A RUBBLE MOUND BREAKWATER SLOPE}

be considered independently of each other. Discussion of evidence in favour of either view would exceed the scope of the present study. On the strength, among other data, of the investigation of wave forces on piles by Bretschneider (7) and $y i l s o n(8)$ it is here assumed that the two types of resistance to the motion of the fluid, the one due to drag forc on the cover blocks and the other due to inertial forces, may with sufficient approximation, be estimated separately.

a) Assuming, like Hedar (2), that the well known equations relating to "sand roughness" in pipes may be applied to the very rough surface of a rubble mound breakwater, the resistance, per unit of depth, derived from the velocity of the fluid at any moment, as if the motion were steady, may be written:

$$
R_{b v}=\tau \Delta u=\gamma_{f} z h_{f}=\frac{\gamma^{2} v^{2} \Delta u}{32 g\left(\log _{10} \frac{14.8 \cdot 2}{k}\right)^{2}}
$$

where $h_{f}$ is the loss of head over the distance $\Delta u$ and $k$ is the equifvalent "sand roughness", taken to be equal to some me diameter of the cover blocks. (References: (5), Equations ( 3 and (10) of III, $\S 11$, and (6), Equations (28) and (33) of Chapter VI). Here the depth of water measured normal to the slope, $z$, has been substituted for the hydraulic radius of tr pipe.

Certainly, Eq. (5) can not be expected to apply with too much accuracy to the case considered here. Teinius (9) ir a recent investigation found that in wide channels with actuc sand roughness of 0,5 to $4,0 \mathrm{~mm}$, the factor 14,8 in the denon nator of $\mathrm{Eq}$. (5) should be replaced by the factor 12,4 . IIowever, the degree of roughness in that case was very differen 1 from that of a rubble mound breakwater slope. A few tests mi at the RHRL in June-July 1962 with a channel bottom practica? identical with the cover layer on the brealswater model, refej to in Section $\mathrm{E}$, indicated that within the range of velocitic and depths of water relevant in this case ( $v=$ about $30 \mathrm{~cm} / \mathrm{si}$ to about $90 \mathrm{~cm} / \mathrm{sec}$ and $z=3,3 \mathrm{~cm}$ to $9,7 \mathrm{~cm}$ ), $\mathrm{Eq}$. (5) gave a fair representation of the resistance to a steady current.

Nevertheless, it is of course possible that in our case the Prandtl equation, (5), should be replaced by some other relationship. There has, however, been no possibility of further study of this problem, aside from the few tests, ferred to above. In view of the confirmatory indications ap from them, it was felt that for the present purpose Eq. (5) tentatively be applied. Certainly, however, the problem of turbulent shear in cases where $k$ and $z$ are of the same order of magnitude needs clearing up. 


\section{COASTAL ENGINEERING}

b) The boundary resistance related to the acceleration must be equal to the inertial forces on the cover blocks. Assuming an inertial coefficient $C_{M p}$ for the force paraliel to the slope, and taking the volume of a block to be $\mathrm{C}_{V} \mathrm{k}^{3}$ and the area of the slope occupied by the block to be $\mathrm{C}_{\mathrm{A}} \mathrm{k}^{2}$, we can state this part of the boundary resistance on our alice, " $S_{u}$ ", per unit of depth normal to the paper, to be

$$
R_{b a}=\frac{\delta_{f}}{g} \frac{C_{V}}{C_{A}} k C_{M p} \cdot a \Delta u
$$

Very few facts on which to base an estimate of the proper magnitude of the coefficient of mass, $\mathrm{C}_{\mathrm{Mp}}$, to be appli in the present case, are known to the writer. For a large diameter cylinder, where the theoretical value would be 2,0 , filson (8) indicates figures around $1, b$ for confused sea conditions. For a sphere the theoretical value would be 1,5 . In the model experiments discussed in Section $E$, natural stor were used, whose average largest linear dimension was about twice the average smallest linear dimension, - something between a cylinder, a disc and a sphere. This might suggest a rather large value of CMp, perhaps somewhere between 1,0 and 1,5 , rather closer to the latter value.

On the other hand, only the upper parts of the cover blocks will be fully exposed to the forces from the moving fluid. This shows up in the fact that the value of the drag coefficient, $C_{D}$, derivable from Eq. (5), is very small, only somewhere around 0,1 to 0,1 . Alltogether it has been decide to apply in the present study the value $\mathrm{CMp}_{\mathrm{Mp}}=0,4$.

Further values chosen for use in the following are: $k=6 \mathrm{~cm}, \mathrm{CV}=0,5$ and $\mathrm{C}_{A}=1,0$, which are believed to correspond reasonably well to the dimensions and the shape of the stones actually used in the experiments discussed in section

\section{Calculation of movement of the SLice " $\mathrm{S}_{\mathbf{u}}$ "}

\section{For the Case of Downrush}

The total downward force parallel to the slope, actin on the slice, "S $\mathrm{S}_{\mathrm{u}}$, per unit of depth, is:

$$
F=G \sin \alpha-F_{p}-R_{b v}-R_{b a}
$$

By entering Eq. $(1),(4),(5)$ and (6) and dividing by the mass of the slice, $\frac{1}{g} \Delta u$, we get the acceleration of $\left.t\right]$ slice, directed downward, paraliel to the slope.

$$
\begin{aligned}
& a=\frac{F \cdot g}{\gamma^{2} z \Delta u}=g \sin \alpha-g \tan \beta \cos \alpha \\
& -\frac{v^{2}}{32 z\left(\log _{10} \frac{14,8 z}{L}\right)^{2}}-\frac{C_{V}}{C_{A}} \frac{k}{z} C_{M_{p}} \cdot a
\end{aligned}
$$




\section{A SIMPLE MATHEMATICAL MODEL OF WAVE MOTION \\ ON A RUBBLE MOUND BREAKWATER SLOPE}

By entering Eq. (3) in Eq. (2) it may be seen that the two first members on the right hand side of $\mathrm{Eq}$. (7) repre sent $a_{0}$, the acceleration which we would have with no boundar resistance.

Eq. (7) can be written:

$$
\frac{d v}{d t}=A^{2}-\frac{v^{2}}{B^{2}}
$$

where

$$
\begin{aligned}
& A^{2}=\frac{g(\sin \alpha-\tan \beta \cos \alpha)}{1+\frac{C_{k}}{C_{A}} \frac{k}{z} C_{M p}} \\
& B^{2}=\left(1+\frac{C_{K}}{C_{A}} \frac{k}{z} C_{M p}\right) 32 z\left(\log _{10} \frac{14,8 z}{k}\right)^{2}
\end{aligned}
$$

It is seen that $A^{2}$ and $B^{2}$ contain no term variable with the motion of the particular slice " $S_{u}$ ", although $z=u t$ varies from one slice to another. Therefore $\mathrm{A}^{2}$ and $\mathrm{B}^{2}$ are invariant with respect to $t$, and $\mathrm{Eq}$. (8) has the solution:

$$
v=A B \operatorname{Tanh}\left(\frac{A}{B} \cdot t\right)+C
$$

Taking $t=0$ at the moment of start of downrush, when $v=0$, we obtain the downward velocity at any moment, $t$,

$$
v=A B \operatorname{Tanh}\left(\frac{A}{B} \cdot t\right)
$$

and the distance, $x$, travelled from the highest position of the slice:

$$
x=B^{2} \ln \left(\operatorname{Cosh}\left(\frac{A}{B} \cdot t\right)\right)
$$

while the acceleration at any moment is:

$$
a=\frac{A^{2}}{\operatorname{Cosh}^{2}\left(\frac{A}{B} t\right)}
$$

\section{For the Case of Uprush}

If the slice " $S_{u}$ " moves up the slope, instead of down which of course presupposes an initial upward velocity, $v_{0}$, the only change in the basic equation (7) will be that the si of the third member on the right hand side changes from - to 


\section{COASTAL ENGINEERING}

(Note that $F, a, v$ and $x$ all are still considered as positiv when directed downward). Instead of $\mathrm{Eq}$. (8) we get:

$$
\frac{d v}{d t}=A^{2}+\frac{v^{2}}{B^{2}}
$$

where $\Lambda$ and $B$ are given in Eq. (9) and (10). The solution for $v$ now is:

$$
v=A B \tan \left(\frac{A}{B} t\right)+C
$$

Tf we assume that at $t=0$ our slice " $S_{u}$ " just passe the line if N, Fig. 2, going up with a velocity

$$
v_{0}=-\sqrt{F_{w} g H}
$$

where $I$ is the wave helght in front of the breakwater and $\mathrm{C}_{\mathrm{W}}$ is a cocficient, we find that at a later moment, $t$,

$$
v=-\sqrt{C_{w} g}+A B \tan \left(\frac{A}{B} t\right)
$$

our particular slice "Su" rcaches its top position, where $v=0$, when $t$ is equal to

$$
t_{0}=\frac{B}{A} \operatorname{arc}\left(\tan =\frac{\sqrt{\epsilon_{w} g H}}{A B}\right)
$$

.e further get:

$$
x=-\sqrt{C_{w} g H} t-B^{2} \ln \cos \left(\frac{A}{B} t\right)
$$

and

$$
a=\frac{A^{2}}{\cos ^{2}\left(\frac{A}{B} t\right)}
$$

In this case the zero point for $x$, at $t=0$, will be at the line $M N$, Fig. 2, instead of at the top, 0 . And sinc different slices pass this line at diffcrent times, the zero moment, $t=0$, will vary from slice to slice.

Let the common datum of reference for the time apply to all slices be the moment when a certain slice, " $S_{u}$ ", passe the line $M N$, let the total time elapsed from that moment be designated as $\sigma$, and let the time when slices " $S_{n+\Delta u ", ~} S_{n+2}$ $" S_{n+3} \Delta u^{\prime} \ldots \ldots$ pass $M N$ be designated as $\sigma_{1}, \sigma_{2}, \sigma_{3}, \ldots$ respectively. Let it further be assumed that all slices pass 


\section{A SIMPLE MATHEMATICAL MODEL OF WAVE MOTION ON A RUBBLE MOUND BREAKW ATER SLOPE}

M N with the velocity $v=v_{0}(E q .(15))$ and with no gap between them. The moment, $\sigma_{p}$, when the slice " $S_{n+p} \Delta u^{\prime}$ passes $M N$ is then given by:

$$
\sigma_{p}=\frac{p \Delta u}{v_{0}}
$$

The position of the slice " $\mathrm{S}+\mathrm{p} \Delta \mathrm{u}$ " at any subsequent moment $\sigma$, provided $\sigma_{p}<\sigma<\left(\sigma_{p}+t_{0}\right)$ can now be calculated from Eq. (18) by entering

$$
t=\sigma-\sigma_{p}
$$

\section{E. COMPARISON WITH EXPERIMENTS}

Extensive studies will be required to establish range of applicability of the model and what values of $l_{u}$ and $\beta$, should be used under different conditions. Such elaboration has not hitherto been possible.

To obtain at least a preliminary indication of the degree of compatibility of the model with real motion, a com. parison has been made of the results of calculation by means of the model, with detail studies of the actual motion in three specific cases.

The downrush motion of three different test waves, with wave heights and periods: $H=15,5 \mathrm{~cm}, T=1,6 \mathrm{sec}$, $H=15,5 \mathrm{~cm}, T=2,1 \mathrm{sec}$, and $H=21,3 \mathrm{~cm}, T=2,1$ sec resper tively were studied. In all three cases the wave was run against a $1: 1,5$ slope of a breakwater model in the $60 \mathrm{~cm}$ wid, wave channel of the RHRL. The depth of water from SWL was 71 and the distance from the breakwater slope at SWL to the wavi paddle was $23,2 \mathrm{~m}$.

In F1g. 5, a) to d), are shown four photographs from a series taken by a motion picture camera during one wave sy of Test Run $1 .{ }^{*}$ )

The white dots and lines seen in the water are due $t_{1}$ confetti introduced to indicate velocities. Although the dis of confetti could show up in the pictures only when turning flat side more or less directly against the camera, still a of them should be expected to be visible during most of the posure, and thus indicate velocities close to the real ones.

\footnotetext{
*) The photographs were taken as part of an investigation carried out by Mr Alf Torum, Laboratory Engineer at the RH
} 
COASTAL ENGINEERING

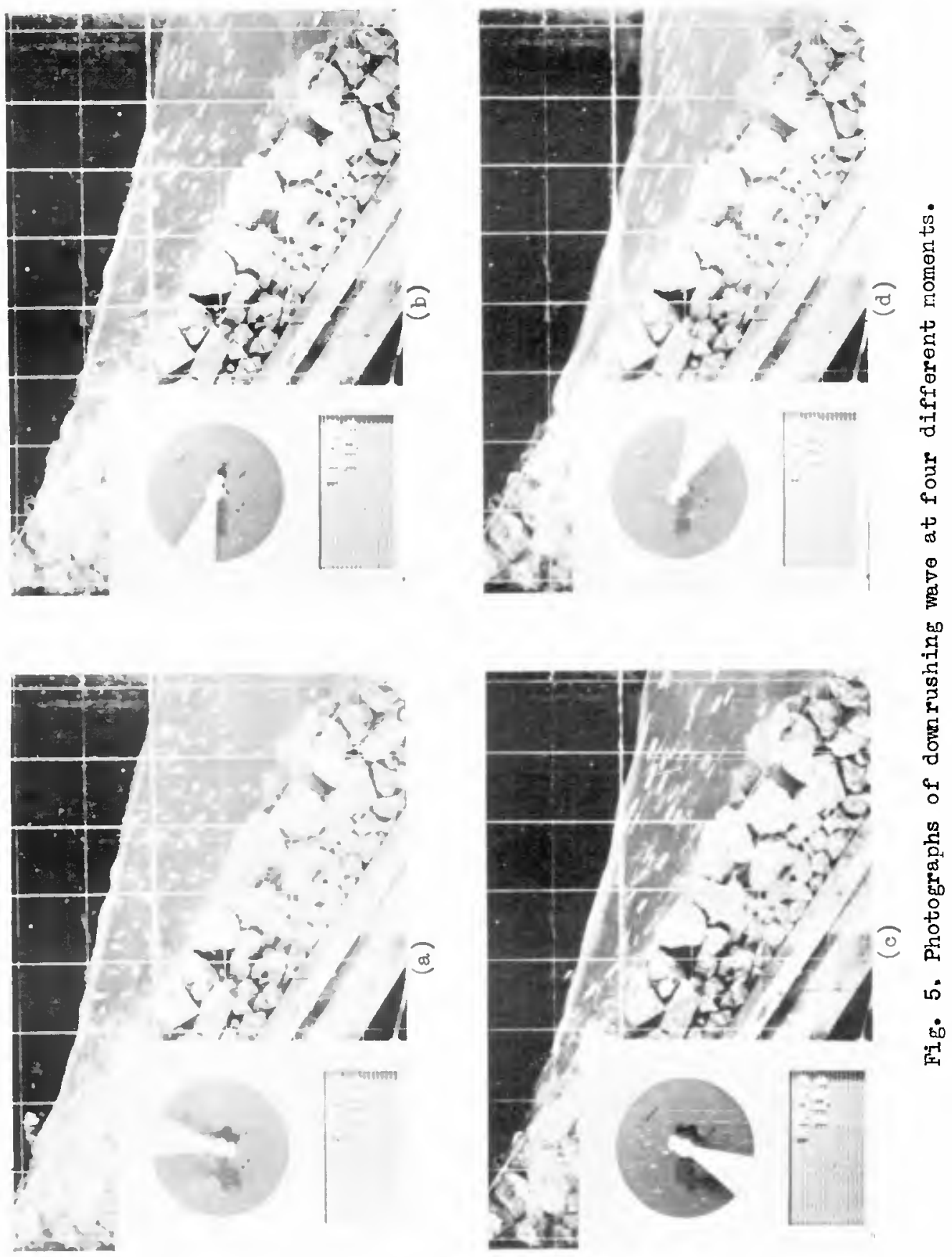


A SIMPLE MATHEMATICAL MODEL OF WAVE MOTION ON A RUBBLE MOUND BREAKW ATER SLOPE
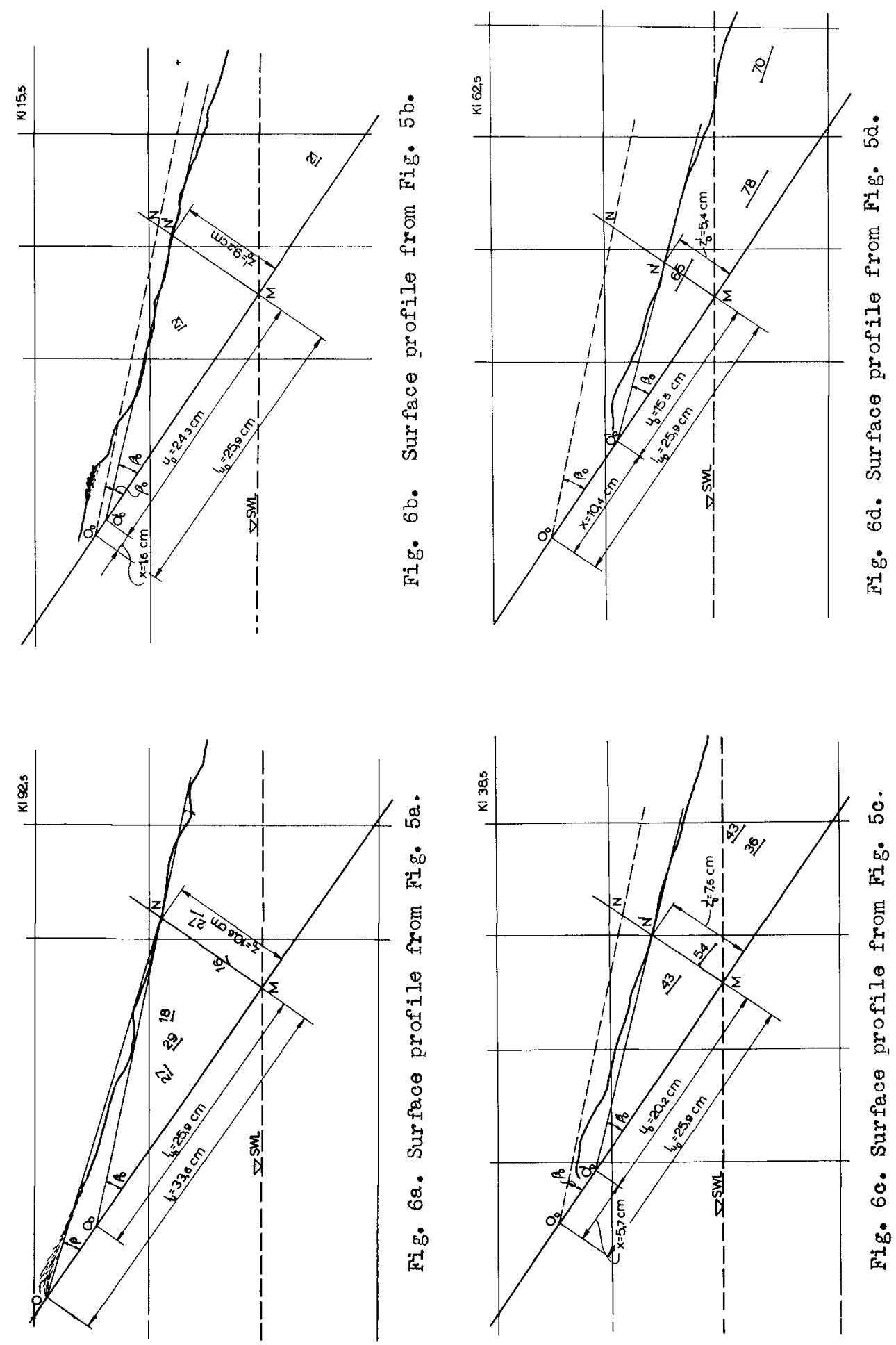


\section{COASTAL ENGINEERING}

Picture a) obviously was taken very nearly at the start of downrush, *) and picture d) shortly before the entire body of water had passed the SWL. The lengths of time between each start of exposure are indicated by the rear edge of the shadow left by the hand of the clock on the pictures and the duration of exposures by the width of this shadow, less the width of the hand itself. The hand moved anti-clockwise one full revolusion in $1 / 2$ second.

In the pictures are seen the white lines drawn on the glass panel of the wave channel, indicating the theoretical front line of the cover layer, the SWL and a grid of horisontal and vertical lines $10 \mathrm{~cm}$ apart.

Projections of the picture, to about one-half of natural size, were made on sheets of paper on which were traced off, besides the lines on the glass panel, the upper edge of the water at the panel, indicating the surface profile at the start of exposure. (Fig. 6, a) to d)). A few of the longer lines traced by the confetti in each picture also were marked off, and the corresponding velocities, in $\mathrm{cm} / \mathrm{sec}$, noted on the sheets. The number at the upper right hand corner of each sheet shows the reading of the clock at the start of exposure, the unit being $1 / 200$ of one second.

In the drawing, Fig. 6 a), the highest point of uprush was estimated to be at 0 , and the length of uprush (see Fig. 2) to be $1_{u}=33,6 \mathrm{~cm}$, while at SWL the depth, $M N$, of water normal to the slope was $z_{0}=10,6 \mathrm{~cm}$, and, determined in this way, $\tan \beta=0,316$.

However, due to some spray around the upper tip of the downrushing water, definition of the point 0 in Fig. 6 a) and of the points corresponding to $0^{\prime}$ (Fig. 2) in the subsequent pictures was rather difficult.

Moreover, as previously explained, our predominant concern is with the situation at SWL, in the region of expecte failure. In particular the value of the angle $\beta$ to be applied should correspond to the actual slope of the water surface at SWL, rather than to the line $0 \mathrm{~N}$.

Therefore, in Fig. 6 a) to d), tangents $0_{0} \mathrm{~N}$, respectively $0^{\prime} N^{\prime}$, were drawn to the surface profile at SW, and the triangles $0_{0} M N$, respectively of $\mathrm{MN}^{\prime}$, with their top angles $\beta$ were taken as representative of the slice just passing the SwL at the moment indicated in each figure. The distances $0_{0}-0_{0}$ $l_{\text {uo }}-u_{0}$ in Fig. $\left.6, b\right)$ to d), accordingly represent the distance, $x$, travelied by that particular slice until the moment stated.

*) In this picture the confetti shows the whole of the visible body of water to be nearly at rest or in only slight and ver confused motion. 


\section{A SIMPLE MATHEMATICAL MODEL OF WAVE MOTION ON A RUBBLE MOUND BREAKWATER SLOPE}

For comparison, the values of $x$ corresponding to the three different values of $t$ at the moments of Fig. $b$ and $6, b)$. c) and d) have been calculated as outlined in sections $C$ and $D$. as well as the velocities and accelerations. In this calculation the particular values of $u_{0}$ and $\beta_{0}$ found from each of the three pictures were used.

It should be especially noted that the calculations concern in all cases the particular slice "Su", which is just passing the SWL at the moment considered.

The results are stated in Table $I$. It is seen that there is a fair agreement between the measured values of $x$ and those calculated as described above. 1t seems therefore probable that also the velocities and accelerations calculated on the same basis should not be too far off from the actual value

While such application of the model in the interpretation of one particular set of test data is not without interes since approximate figures for accelerations and velocities are obtained, a wider applicability of the model depends on the possibility of basing the calculation on a simpler and more general set of parameters, not to be determined separately for each moment considered.

The total length of uprush along the slope, lu, Fig.2 and Fig. 6 a), the variation of which with wave and brealswater characteristics has already been widely studied, is proposed as one such parameter. The other parameter must be some angle $\beta$, selected on the basis of test data.

For reasons already stated, $\beta$ should be selected with rogard to the situation at the SilL, rather than at the top of uprush. In the present case tan $p$ was chosen as the average 0 the measured values stated in the table, ommitting, however, the figure corresponding to the moment, $t=0$, when there was as yet no motion.

Using the value of $\tan \beta$ thus selected, together with the measured value of $l_{u}$ (Fig. 6 a)), a set of $x$-, v- and avalues have been calculated and included in Table $I$.

It is seen that these figures do not deviate materiall from those found by the previous calculation.

The two subsequent test runs, No 2 and No 3 , were made and interpreted in the same manner as run No 1 , except that nc confetti was used. Only the results are reproduced here, in $T$ c II and III. 
Table I

MEASURED AND CALCULA TED QUANTI TES COIJPARED Test Run 1

$H=15,5 \mathrm{~cm}, T=1,6$ sec $(F i g .5, a)$ to d) and Fig. 6,a)

\begin{tabular}{|c|c|c|c|c|c|c|c|c|c|}
\hline \multicolumn{4}{|c|}{ Measured Quantities } & \multicolumn{6}{|c|}{ Quantities calculated with } \\
\hline \multirow{2}{*}{$\begin{array}{l}\text { Clock } \\
\text { Readings } \\
1 / 200 \\
\text { sec }\end{array}$} & \multirow{2}{*}{$\begin{array}{c}t \\
\sec \end{array}$} & \multirow{2}{*}{$\begin{array}{l}x \\
c m\end{array}$} & \multirow[t]{2}{*}{$\tan \beta_{0}$} & \multicolumn{3}{|c|}{$\begin{array}{c}\boldsymbol{l}_{u_{0}} \text { or } u_{0} \text { and } \beta_{0} \\
\text { as measured }\end{array}$} & \multicolumn{3}{|c|}{$\begin{array}{l}\mathbf{l}_{u}=33,6 \mathrm{~cm} \\
\tan \beta=0,367\end{array}$} \\
\hline & & & & $\begin{array}{r}\mathbf{x} \\
\mathrm{cm}\end{array}$ & $\begin{array}{c}v \\
\mathrm{~cm} / \mathrm{sec}\end{array}$ & $\begin{array}{c}\mathrm{a} \\
\mathrm{cm} / \mathrm{sec}^{2}\end{array}$ & $\begin{array}{r}\mathrm{x} \\
\mathrm{cm}\end{array}$ & $\begin{array}{c}\mathrm{v} \\
\mathrm{cm} / \mathrm{sec}\end{array}$ & $\mathrm{cm} / \mathrm{sec} \mathrm{c}^{2}$ \\
\hline 92,5 & 0 & 0 & 0,409 & 0 & 0 & 186 & 0 & 0 & 224 \\
\hline 15,5 & 0,115 & 1,6 & 0,378 & 1,4 & 24 & 208 & 1,5 & 26 & 222 \\
\hline 38,5 & 0,230 & 5,7 & 0,376 & 6,1 & 47 & 200 & 5,8 & 50 & 217 \\
\hline 62,5 & 0,350 & 10,4 & 0,348 & 12,9 & 72 & 194 & 12,8 & 73 & 206 \\
\hline
\end{tabular}

Table II

MEASURED AND CALCULATED QUAN TI TIES COIIPARED Tost Run 2

$$
\mathrm{H}=15,5 \mathrm{~cm}, \mathrm{~T}=2,1 \mathrm{sec} \text {. }
$$

\begin{tabular}{|c|c|c|c|c|c|c|c|c|c|}
\hline \multicolumn{4}{|c|}{ Measured Quantıtıes } & \multicolumn{6}{|c|}{ Quantities calculated with } \\
\hline \multirow{2}{*}{$\begin{array}{l}\text { Clock } \\
\text { Readings } \\
1 / 200 \\
\text { sec }\end{array}$} & \multirow{2}{*}{$\begin{array}{c}t \\
\sec \end{array}$} & \multirow{2}{*}{$\begin{array}{r}\mathbf{x} \\
\mathrm{cm}\end{array}$} & \multirow{2}{*}{$\tan \beta_{0}$} & \multicolumn{3}{|c|}{$\begin{array}{l}l_{\text {uo }} \text { or } u_{0} \text { and } \beta_{0} \\
\text { as mearured }\end{array}$} & \multicolumn{2}{|c|}{$\begin{array}{l}\mathbf{l}_{\mathbf{u}}=38,1 \mathrm{~cm} \\
\tan \beta=0,329\end{array}$} & \\
\hline & & & & $\begin{array}{r}x \\
\mathrm{~cm}\end{array}$ & $\begin{array}{c}\mathrm{v} \\
\mathrm{cm} / \mathrm{sec}\end{array}$ & $\begin{array}{cc}a & \\
\mathrm{~cm} / \mathrm{sec}\end{array}$ & $\begin{array}{r}\mathbf{x} \\
\mathrm{om}\end{array}$ & $\begin{array}{c}v \\
\mathrm{~cm} / \mathrm{sec}\end{array}$ & $\mathrm{cm} / \mathrm{sec}^{2}$ \\
\hline 08 & 0 & 0 & 0,407 & 0 & 0 & 202 & 0 & 0 & 276 \\
\hline 32 & 0,120 & 0,8 & 0,362 & 1,7 & 27 & 227 & 2,0 & 30 & 250 \\
\hline 55 & 0,235 & 5,8 & 0,329 & 6,7 & 57 & 241 & 6,8 & 58 & 243 \\
\hline 81 & 0,365 & 13,7 & 0,320 & 16,0 & 86 & 224 & 15,6 & 85 & 221 \\
\hline 04 & 0,480 & 23,5 & 0,306 & 24,5 & 97 & 161 & 24,3 & 96 & 173 \\
\hline
\end{tabular}




\section{A SIMPLE MATHEMATICAL MODEL OF WAVE MOTION ON A RUBBLE MOUND BREAKWATER SLOPE}

Table III

IEASURED AND CALCUIATED QUANTI TES COIPARED Test Run 3

$\mathrm{H}=21,3 \mathrm{~cm}, \quad \mathrm{~T}=2,1 \mathrm{~s} \theta \mathrm{c}$.

\begin{tabular}{|c|c|c|c|c|c|c|c|c|c|}
\hline \multicolumn{4}{|c|}{ Ifecsured ?uantities } & \multicolumn{6}{|c|}{ Juantities calculated with } \\
\hline \multirow{2}{*}{$\begin{array}{l}\text { Clock } \\
\text { ileadings } \\
1 / 200 \\
\text { sec }\end{array}$} & \multirow{2}{*}{$\begin{array}{c}t \\
\sec \end{array}$} & \multirow{2}{*}{$\begin{array}{l}x \\
\mathrm{~cm}\end{array}$} & \multirow[t]{2}{*}{$\tan \beta_{0}$} & \multicolumn{3}{|c|}{$\begin{array}{l}1_{\text {uo }} \text { or } u_{0} \text { and } \beta_{0} \\
\text { as measured }\end{array}$} & \multicolumn{3}{|c|}{$\begin{array}{l}1_{u}=53,0 \mathrm{~cm} \\
\tan \beta=0,257\end{array}$} \\
\hline & & & & $\begin{array}{r}x \\
\mathrm{~cm}\end{array}$ & $\begin{array}{c}\mathrm{v} \\
\mathrm{cm} / \mathrm{sec}\end{array}$ & $\mathrm{cm} / \mathrm{sed}$ & $\begin{array}{c}x \\
\mathrm{~cm}\end{array}$ & $\begin{array}{c}\mathbf{v} \\
\mathrm{cm} / \mathrm{sec}\end{array}$ & $\stackrel{a}{c m / s e c^{2}}$ \\
\hline 22,5 & 0 & 0 & 0,321 & 0 & & 263 & 0 & 0 & 306 \\
\hline 46,5 & 0,120 & 2,6 & 0,289 & 2,0 & 34 & 283 & 2,2 & 37 & 305 \\
\hline 70,5 & 0,240 & 9,4 & 0,278 & 8,2 & 68 & 281 & 8,7 & 72 & 297 \\
\hline 96,0 & 0,368 & 13,4 & 0,244 & 19,9 & 107 & 274 & 19,7 & 106 & 273 \\
\hline 19,6 & 0,483 & 30,2 & 0,217 & 31,2 & 124 & 204 & 30,8 & 123 & 219 \\
\hline
\end{tabular}

Table IV

CALCUIA TED VAIUES OF THE ACCELERA TION AT SWL A T THE INOMENT OF MAXIIUM BOUNDARY RESTS DANCE A T SWL

$\tan \beta=0,367$

\begin{tabular}{|c|c|c|c|c|c|c|}
\hline \multirow[b]{2}{*}{$\begin{array}{l}\mathrm{H} \\
\mathrm{cm}\end{array}$} & \multirow[b]{2}{*}{$\begin{array}{l}\mathrm{I}_{\mathrm{u}} \\
\mathrm{cm}\end{array}$} & \multicolumn{5}{|c|}{ At $R_{b \max }=\left(R_{b v}+R_{b a}\right)_{\max }$} \\
\hline & & cri & $\begin{array}{l}\mathrm{u}_{\mathrm{o}} \\
\mathrm{cm}\end{array}$ & $\begin{array}{l}\mathbf{x} \\
\mathrm{cm}\end{array}$ & $c=\frac{a}{c m} \sec ^{2}$ & $\begin{array}{c}R_{b} \max / \Delta u \\
g / \mathrm{cm}^{2}\end{array}$ \\
\hline 15,50 & 33,6 & 0,56 & 8,1 & 25,4 & 105,0 & 0,423 \\
\hline 19,38 & 42,0 & 0,63 & 9,2 & 32,8 & 106,5 & 0,476 \\
\hline 23,25 & 50,4 & 0,68 & 10,6 & 39,8 & 112,8 & 0,523 \\
\hline 27,13 & 58,8 & 0,73 & 11,8 & 47,0 & 116,1 & 0,568 \\
\hline
\end{tabular}




\section{COASTAL ENGINEERING}

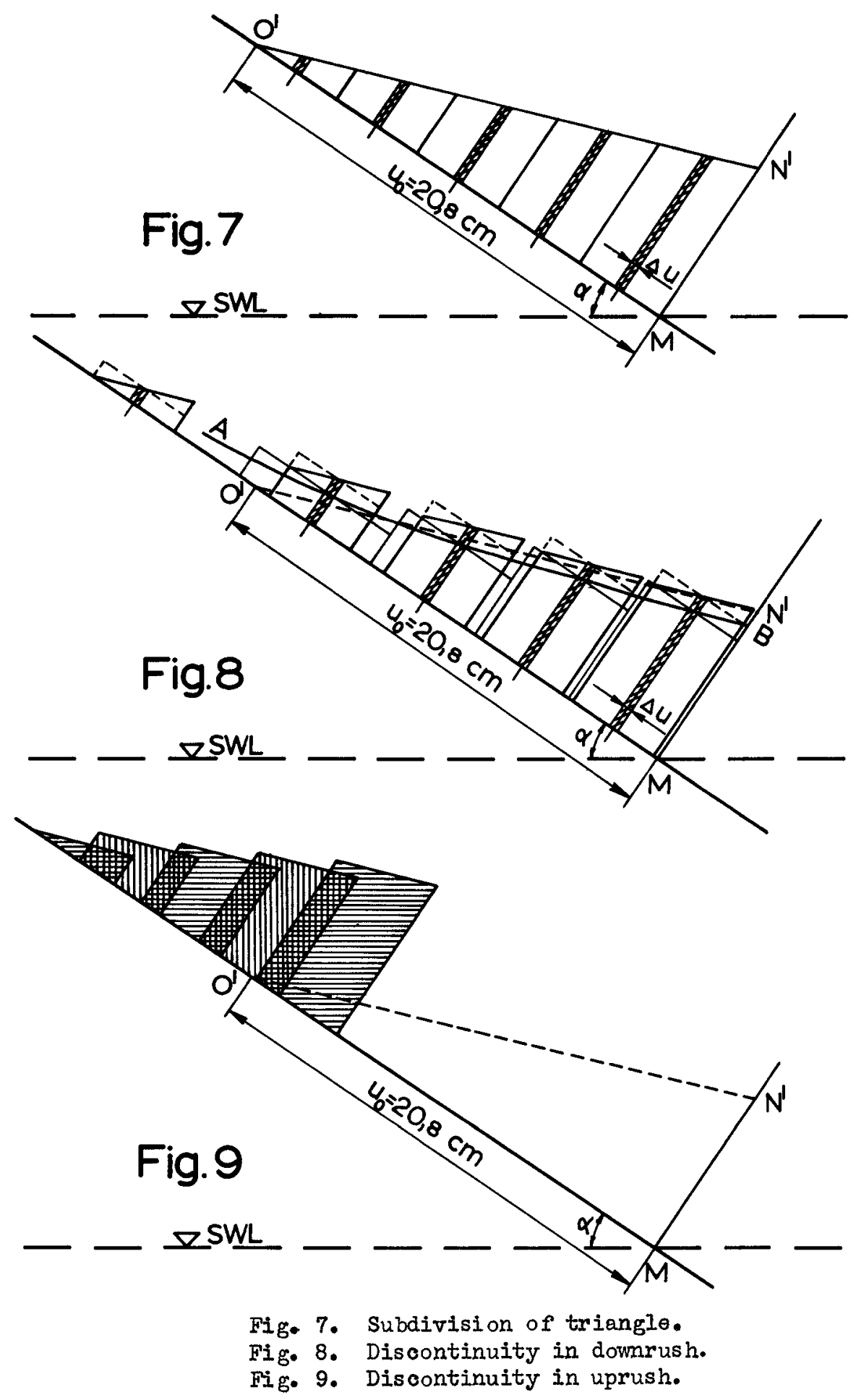




\section{A SIMPLE MATHEMATICAL MODEL OF WAVE MOTION \\ ON A RUBBLE MOUND BREAKWATER SLOPE}

It is seen from the tables that also in these cases there is fair agreement ${ }^{*}$ ) between measured and calculated values of $x$, as well as betwen $x-, v-$ and a-values calculated from direct measurement of individual values of $l_{u_{0}}, u_{o}$ and $\beta_{o}$, and those calculated from the actual maximum length of uprush in the test, $1_{u}$, with $\tan \beta$ equal to the average of all but the first one of the individual values.

\section{F. DISCONTINUITY OF THE MODEL}

\section{In the Case of Downrush}

As stated in paragraph 3 of Section $B$, the slices into which the body of water on the breakwater slope is thought to be subdivided, are assumed to be moving independently of each other, without regard to continuity. Since this assumption cannot possibly be correct, it is important to get some indication as to what is the actual extent of the discontinuity inherent in the model, and how this should be expected to affect its applicability.

For this purpose a study was made of one particular case: that presented in the last three columns of Table $I$, at the time $t=0,35 \mathrm{sec,} \mathrm{with} x=12,8 \mathrm{~cm}$. Since $1_{u}=33,6 \mathrm{~cm}$, the value of $u_{0}$ for the particular slice just then passing the SWL is $20,8 \mathrm{~cm}$. (For notation, see Fig.2).

The study was made as follows: By dividing 0 'M
(Fig. 2) into five equal pieces and raising normals to the slope in the dividing points, the triangle $0^{\prime} \mathrm{M} \mathrm{N}^{\prime}$ was divided into five parts (Fig. 7). Next, the movement, $x$, from their top position, of siices located at the middie of the base of each of these five parts was calculated for the time $t=0,35 \mathrm{sec}$.

The result is shown in Fig. 8. The five slices have moved differently. Assuming that each of the five parts will move as the middle of its base, without change of shape, ther will at $t=0,35$ sec be the gaps between the parts shown in the figure. Near the Sill the gaps are rather insignificant, they increase, however, very much close to the top, which is natural, since the resistance must there be great, due to the low values of $z$.

*) The difference seen in Table II between measured and calculated values of $x$ for $t=0,120 \mathrm{sec}$ may be due to the first exposure in the series starting, not at $t=0$, but slightly later. 
Continuity might be restored, if, in the process of motion, the several parts were made to decrease in height and increase in width without change of area, until they touched. We should then have a surface at $t=0,35$ somewhat like the curve A-B in Fig. 8 .

of course this transformation of the surface would not compensate for the discrepancies in our model, inherent in the assumption that $z$ is invariant with respect to $t$. But it seems plausible to assume that the surface profile $A-B$ in Fig. 8 gives an indication of what the real surface would be like. The profile A-B agrees quite well with what is generally seen in tests.

In Fig. 7 the surface line $0^{\prime} N^{\prime}$ of the original triangle has been drawn as a dotted line. It seems reasonab to conolude from the figure that calculation based on the su face $O^{\prime} N^{\prime}$ may be expected to conform fairly well to actual motion, as far as regions not too close to the top of the triangle are concerned.

It also seems reasonable to consider Fig. 8 as a confirmation of the expediency of basing the calculations of Section $E$ on the surface slope at SIV, rather than at points nearer the top.

\section{In the Case of Uprush}

As already stated, useful numerical treatment of the uprushing wave by means of our model can hardly be possible. Nevertheless a calculation has been made, by means of the fo mulae of Section $D$, and using the same method of dividing the same triangle $0^{\prime} \mathrm{M} N^{\prime}$ into five parts and calculating the motion, as used for Fig. 8. In Fig. 9 is shown the position of the five parts at the moment, $t_{0}(\mathrm{Eq} \cdot 17)$, when the middl slice of the top triangle stops. The initial velocity, $v_{0}$, has been taken to be $v_{0}=\sqrt{1,3 \mathrm{gH}}=141 \mathrm{~m} / \mathrm{sec}$ when $\mathrm{H}=15$, !

As seen from the figure, the five parts would, accors ing to this calculation, overlap. In actual motion the wates towards the end of uprush would pile up higher, with a great, $z_{0}$ and a greater angle $\beta$, than the model would indicate. Pent tration of some water into the body of the breakwater probab: would partly counteract this development. It is submitted ti there is a fair qualitative agreement between the model and actual experience also in the case of uprush.

\section{G. BOUNDARY RESISTANCE}

A point of particular interest is the magnitude of the boundary resistance to the motion of the fluid due to dre 


\section{A SIMPLE MATHEMATICAL MODEL OF WAVE MOTION ON A RUBBLE MOUND BREAKW ATER SLOPE}

and inertial forces. (Eq. (5) and (6)). In Fig. 10 the drag and inertial boundary resistance per unit of area of the slice just passing the $\mathrm{S} V L$, and their total, $\mathrm{R}_{\mathrm{b}} / \Delta \mathrm{u}$, have been plotted against the time, $t$, from start of downrush and also against $u_{o}$, the remaining length of the triangle belonging to the slice just passing the SWL $\left(u_{0}=1_{u}-x\right)$, at the time, $t$.

It is seen that at the start of downrush the inertial forces are dominating, but as velocity increases the drag forces become more important, and towards the end, dominating. The total, $R_{b} / \Delta u$, at $S W L$, reaches a maximum fairly late in the process of downrush.

The curves in Fig. 10 were calculated with $1_{u}=33,6$ c and $\tan \beta=0,367$, for the case $H=15,5 \mathrm{~cm}$ and $T=1,6 \mathrm{sec}$. This is the same case as treated in the last three columns of Table I, although the calculation has been carried on to higher values of $t$ and $x$ than covered by the table. Similar curves have been drawn for the cases $\mathrm{H}=19,4 \mathrm{~cm}, 23,3 \mathrm{~cm}$ and $27,1 \mathrm{~cm}$, assuming $l_{u}$ to vary in direct proportion to $H$ and $\tan \beta=0,367$ in all cases.

The curves all show a maximum value of $R_{b}$ at fairly high values of $t$ and $x$, rather far out on the doubtful side of Fig. 8. Still the maximum ralues of $R_{b} / \Delta u$ in the four cases have been listed in Table IV, together with the corresponding values of $t, x, u_{0}$ and $a$.

Interesting is that at $R_{b} \max$ the calculated accelera tion is nearly the same in all cases, on an average around $110 \mathrm{~cm} / \mathrm{sec}^{2}$. It seems probable that due to the shortcomings of the model, the maximum may actually occur somewhat earlier at lower values of $x$ and higher values of $a$, than indicated by the model. From consideration of both Table $I$ and Table $I$ it seems to be indicated that at the point of maximum boundar resistance at SWL the acceleration will be somewhere between 100 and $200 \mathrm{~cm} / \mathrm{sec}^{2}$, probably closer to the former, and will not vary very much with the wave height.

Another point to be noted is the surprisingly low values of the total resistance, $R_{b}$, indicated by the model. Actually it is a matter of only a couple of hundred $\mathrm{kg}$ pr sq of the slope surface, translated to full scale conditions.

Directly this result is due to the assumptions made in Section $C, 3$, with regard to resistance relations and the coefficients to be applied to them. The apparent agreement between the model and actual motion found in the three cases discussed previously, might possibly indicate that the assump tions made are not too far from reality, but of course the 


\section{COASTAL ENGINEERING}

Table V

Calculation of $x, v$ and a with Particular values of $\tan \beta$, or with $\tan \beta=0.3$.

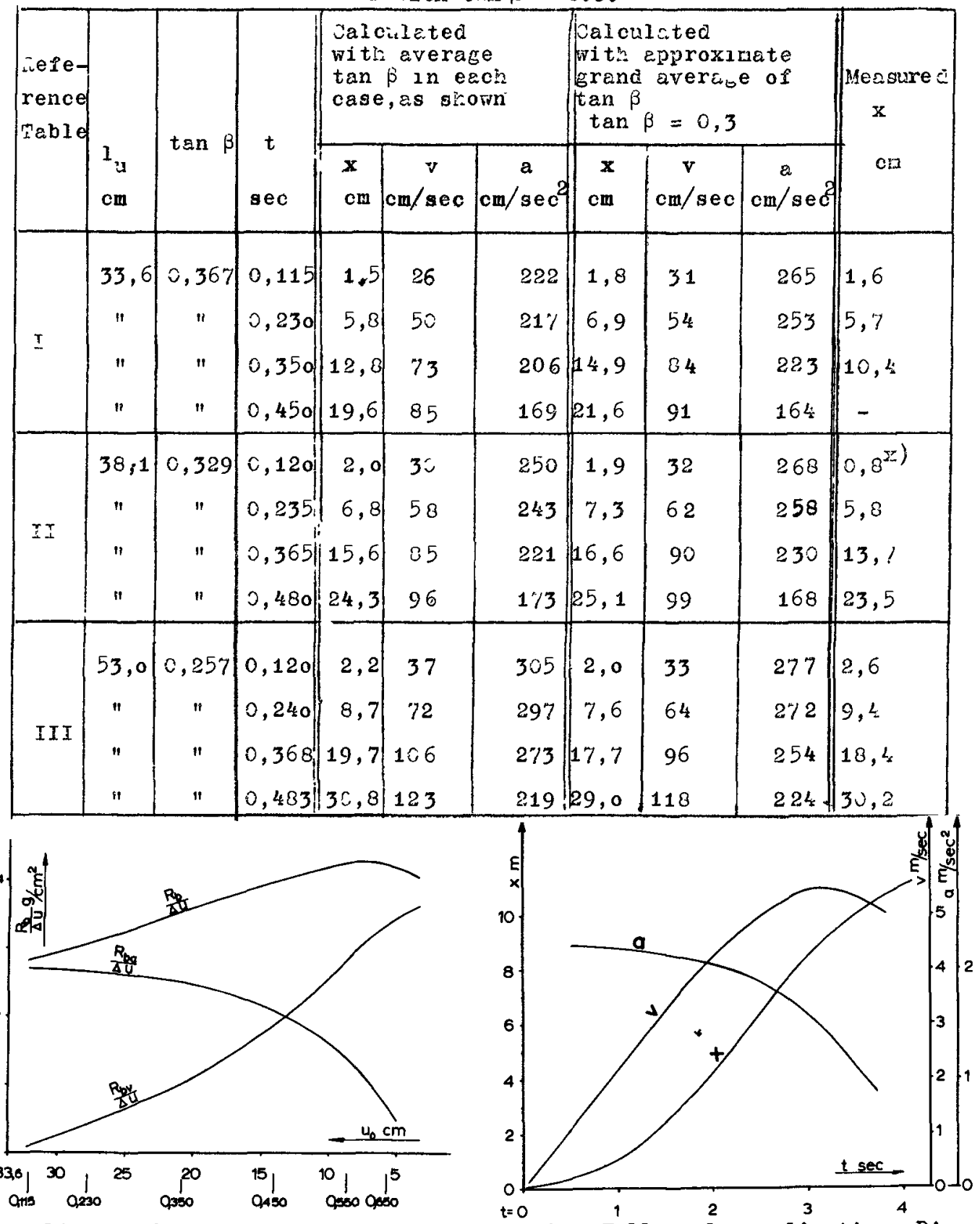

Fig. 10. Boundary forces plotted against $u_{0}$ (remaining length of triangle above SWL), and against $t$, time Fig. 11. Full scale application. Displacements, velocities and accelerations for $\mathrm{H}=40 \cdot 15.5=620 \mathrm{~cm}$. since start of downrush. 


\section{A SIMPLE MATHEMATICAL MODEL OF WAVE MOTION ON A RUBBLE MOUND BREAKWATER SLOPE}

evidence is entirely insufficient as a basis of any such conclusion. In the present context the main interest lies with the indication that the model may actually prove helpful in the study of these boundary forces.

\section{H. FULL SCALE APPLICATION}

In Fig. 11 has been shown how the model works out when applied to full scale dimensions. Curves for the variation of $x, v$ and a with $t$ have been computed for a case with lineal dimensions 40 times those of the first test run, Table using $\tan \beta=0,367$, as in the last three columns of Table $I$. Comparison with Table I shows that the relations between the $x-, v-$ and a-values for the two scales follow closely Froude's law.

Curves similar to those of Fig. 10, showing the variation in boundary resistance during downrush, have been prepare but are not included here. They are quite analogous to those of Fig. 10. The maximum total resistance at SWL is found at about $t=3,5$ seconds, corresponding to about $x=10,2 \mathrm{~m}$. Since $l_{u}$ has been taken to be 40 times $0,336 \mathrm{~m}=13,4 \mathrm{~m}, u_{0}$ for the slice just passing the SiV at the time of maximum resistance is $u_{0}=1_{u}-x=3,2 \mathrm{~m}$. Again the maximum resistar at SWL is found to be very small, only about $170 \mathrm{~kg} / \mathrm{m}^{2}$.

As mentioned before, it may possibly be proper to consider, not the SirL, but a section even as much as one wholf wave height lower, as the critical one. In that case $l_{u}$ becon $13,4 \mathrm{~m}+40 \cdot 0,155 / \sin \alpha=24,6 \mathrm{~m}$.

Calculation on this basis gives a maximum total resis. tance at the lower critical point of $233 \mathrm{~kg} / \mathrm{m}^{2}$, found at $t=4,8$ sec with $x=20,0 \mathrm{~m}$ and $u_{0}=4,6 \mathrm{~m}$. The corresponding velocity is $7,7 \mathrm{~m} / \mathrm{sec}$ and the acceleration $1,1 \mathrm{~m} / \mathrm{sec}$.

\section{POSSIBILITY OF APPLYING MOHE GENERAL PARAMETERS}

To apply the model one needs to know what values of the parameters $1_{u}$ and tan $\beta$ to use in each case.

The value of $1_{u}$, the actual length of uprush along thi slope, can be calculated from the height of uprush, $h_{u}$, the relation of which to wave and breakwater characteristics have al ready been, and are still being, widely studied in many lab ratories. 


\section{COASTAL ENGINEERING}

About the proper value of $\tan \beta$, on the other hand, no such information is available at present. However, it seems that quite wide variations in the value of $t a n$ does not very much affect the results of calculations based on the mode1. An indication of this is given in Table $v$, where a comparison has been made between the $x-, v-$ and a-values calculated by using the average values of $\tan \beta$ found for each individual test run, and a general value of tan $\beta=0,3$. (The average of the values for the three test runs is $\tan \beta=$ $0,318)$. It is seen that in order of magnitude there is no essential difference between the results.

It is believed that for the type of breakwater considered here, with a front slope of $1: 1,5$ and for waves of ordinary steepness, a general value of $\tan \beta=0,3$ may tentatively be used, where the object is merely to get a general picture of the motion.

\section{CONCLUSIONS}

because:

1. The model presented, crude as it is, seems promis

a) in three different cases where the kinematics of the downrushing wave has been studied in some detail, calculations based on the model yields results well compatibl with actual motion,

b) the discontinuity inherent in the model does $n$ seem to affect too much the general picture of the motion, at least not in the region around the SWL,

c) applied to the case of uprush, the model yield results qualitatively in fair accordance with observed motion

d) when applied to the same case in two different scales ( 1 to 1 and 1 to 40) it yielded results in close agree ment with Froude's law,

e) it seems to provide a useful means of studying wave forces on the cover blocks parallel to the slope.

2. The acceleration of the water down along the slop seems generally to be of magnitude between $200 \mathrm{~cm} / \mathrm{sec}^{2}$ and $300 \mathrm{~cm} / \mathrm{sec}^{2}$ during the first part of the downrushing motion, and to diminish to somewhere between 100 and $200 \mathrm{~cm} / \mathrm{sec}^{2}$ at $t$ moment when the sum of drag and inertial forces passes its maximum. 


\section{A SIMPLE MATHEMATICAL MODEL OF WAVE MOTION ON A RUBBLE MOUND BREAKWATER SLOPE}

3. Only breakwater fronts with a slope of $1: 1, b$ and waves of steepness between 0,03 and 0,05 have been considered in this paper. For such cases it seems that the value of $\tan \beta=0,3$ may be used in approximate calculations.

\section{ACKNOWLEDGEMENT}

First of all the writer is deeply indebted to Mr. E. Palm, Ph.D., Professor of Fluid Mechanics at the Norwegian Technical University, for very needful criticism and correction, and for valuable suggestions. Helpful suggestions from Mr. S.I.O. Selberg, Ph.D., Professor of Mathematics at the same university, are also gratefully acknowledged. The writer further expresses particular gratitude to Mr. Alf Torum, Laboratory Engineer at the Institute of Construction and Harbour Engineering at this university, for making his technique for measuring wave motion on slopes available for this investigation, and for carrying out the tests described. Grateful acknowledgement is also extended to the writer's assistants, Mr. H.P. Sundh, Civil Engineer, and Mr. E. Ellingsen, Civil Engineer, who made the calculations and contributed valuable suggestions.

\section{REFERENCES}

(1) Robert Y. Hudson: "Laboratory Investigations of Rubble Mound Breakwaters", Trans.A.S.C.E., Vol.126,1961, Part IV, p.491.

(2) P.A. Hedar: "Stability of Rock-Fill Breakwaters", Akademiforlaget - Gumperts, Goteborg, 1960.

(3) Roald Svee: "Formulas for Design of Rubble Mound Breakwaters". Proc.A.S.C.E., Vol.88, Ww2, May 1962, Part I, pp.11-21.

(4) Gunnar Sigurdsson: "Wave Forces on Breakwaters". Dissertation, University of California, Berkeley, Ca. October 1961 .

(5) Ludwig Prandtl: "Fuhrer durch die Stromungslehre", Fifth Edition, Friedrich Vieweg und Sohn, Braunschweig 1

(6) Hunter Rouse: "Engineering Hydraulics", Chapman and Hall Ltd., London 1950. 


\section{COASTAL ENGINEERING}

(7) Charles L. Bretschneider: "Evaluation of Drag and Inertial Coefficients from Maximum Range of Total Wave Force", Technical Report No. 55-5, The A and M College of Texas, May 1957. Department of 0ceanography and Meteorology.

(8) Basil W. Wilson: "Results of Analysis of Wave Force Dat Confused SeaConditions round a 30-Inch Diameter Test Pi Gulf of Mexico". Final Technical Report No. 55-7, July The $A$ and $M$ College of Texas, Department of 0ceanography and Meteorology.

(9) Erling Reinius: "Steady Uniform Flow in Open Channels", Bulletin No. 60 of the Division of Hydraulics at the Royal Institute of Technology, Stockholm, Sweden 1961. 